\title{
MOBİL HIDDROLİK TELESKOBİK VİNÇLERDE YÜK SALINIM KONTROLÜ
}

\author{
1Umut YILMAZ, ${ }^{2}$ Mete KALYONCU \\ 1,2 Selçuk Üniversitesi, Mühendislik-Mimarlık Fakültesi, Makina Mühendisliği Bölümü \\ 42079 Alaaddin Keykubad Kampüsü, KONYA \\ umut_yilmaz_26@hotmail.com.tr, mkalyoncu@selcuk.edu.tr
}

(Geliş/Received: 05.06.2014; Kabul/Accepted in Revised Form: 08.07.2014 )

ÖZET: Bu çalışmada, mobil hidrolik teleskobik bir vincin öncelikle tasarımı yapılmış ve burada bir yük ile vinç tanımlanmıştır. Tasarlanan teleskopik vinç gerçek sistemdeki veriler dahil edilerek Matlab/Simulink programında modellenmiştir. Giriş sinyalleri etkisiyle oluşan salınım ölçülüp bu salınımı kabul edilebilir toleranslar dahiline düşürebilecek PID kontrolcüler tasarlanmıştır. PID kontrolcüler matlab programına entegre edilerek simule edilmiştir. Kontrolcülerin sistem üzerinde oldukça etkili olduğu ve istenilen salınım açı değerlerine ulaşılmıştır.

Çalışmanın ana hedefi, mobil teleskobik vinçlerin kaldırma silindirleri ve dönme merkezindeki tork tahriki ile hareket etmesi sonucu teleskobik vince bir halat vasıtasıyla bağlı olan yükün $\mathrm{x}, \mathrm{y}, \mathrm{z}$ referans eksenlerine göre açılı bir şekilde oluşan salınımını kontrolcü kullanarak minimize etmektir. Sistemin başarı kriteri, uygulamada ergonomik bir çalışma zemini hazırlayacak şekilde salınımı azaltmak olacaktır. Göz önüne alınması gereken bir diğer nokta ise vinci kullanacak operatörden bağımsız bir şekilde bu kontrolü sağlamak olacaktır.

Anahtar Kelimeler: Teleskobik Hidrolik Mobil Vinç, Salınım, PID Kontrolcü, Matlab, Simulink, Matematiksel Model, Konum Kontrolü

\section{Sway Control of Mobile Hydraulic Telescopic Cranes}

\begin{abstract}
In this study, first of all mobile hydraulic telescopic crane's design was made and crane with load was defined. Designed telescopic crane that includes real system datas was modelled by using Matlab / Simulink software. The sway that was formed by effect of input signals was measured and PID controller was designed to reduced the sway to an acceptable tolerances. PID controller is integrated into the matlab software and simulation was performed. PID controller on the system has been quite effective and sway angle to the desired value has been reached.

The main goal of this study is to minimize the sway of load which bound up to telescopic crane through a rope, which is made at an angle and this movement is made with respect to $x, y$ and $z$ reference axes, by using controller as a result of moving via torque excitation in mobile telescopic crane's lifting cylinders and center of rotation. The success benchmark of system will be to reduce sway by preparing an ergonomic study base in execution. On the other hand, another important point is that will be to control of crane free of operator will drive.
\end{abstract}

Key Words: Telescopic Mobile Crane, Sway, PID Control, Matlab, Simulink, Mathematical model, Position Control 


\section{GİRIŞ (INTRODUCTION)}

Vinçler düşey ve yatay hareketleri sayesinde genel anlamda her türlü yükün yerini değiştirebilen makinelerdir. $\mathrm{Bu}$ makineler genellikle ağır yüklerin kaldırılmasında ve zemine batmış makinelerin kurtarılmasında kullanılır. Çember dişli üzerinde $360^{\circ}$ dönebilen tipleri olduğu gibi $180^{\circ}$ lik dönüş yapan tipleri de kullanılmaktadır. Destek ağırlıkları ve ayak basma bomları sayesinde ağır yükler kolayca yükü ayaklara dağıtarak kaldırılabilmektedir. Teknik olarak teleskobik vinçler $30^{\circ}$ de yük alır ve yük aldıktan sonra uzatma bomları açılmaz kilit mekanizmaları devreye girer bu şekilde yükü bir yerden başka bir yere aktarabilmektedir. Teleskobik vinçler kaldırma kapasitesinin yüksek olduğu yerlerde tercih edilirler bunlar; inşaat alanları, fabrikalar, silo kurulumları, karayolları, büyük makine parkurlarının hazırlanmasında vb.

Taşımacılıkta kullanılan vinçler, çalışmaları sırasında göz ardı edilemeyecek dinamik yüklerin etkisi altında kalmaktadır. Bu dinamik yük etkisi çoğunlukla yüklerin yapmış olduğu salınımlardan kaynaklanmaktadır. Ancak yükün salınım hareketi, yükün taşınması işleminin verimini ve güvenliğini azaltmaktadır ve teleskobik vinçlerde amaç malzemelerin bulunduğu yerden mümkün olduğunca hızlı alınması, taşınması ve gideceği yere minimum zamanda güvenli bir biçimde ulaşmasını yerine getirmektir. Bu nedenle yükün salınım açısının düşürülmesi son derece önemlidir.

Genel uygulamada vinçlerde salınımı önlemek vinci kullanan operatör insiyatifi ile sürekli salınan yöne doğru ters kısa ivmelenmeler yapmak suretiyle manüel olarak yapılır. Bu durum vinç operatörünün sürekli stres ve yüklü bir konsantrasyon altında çalışmasını zorunlu kılar. Çoğu zaman bu durum yoğun çalışma temposu ile birleştiğinde oluşan insan kaynaklı hatalara bağlı üretim, malzeme ve zaman kayıplarına sebep olmaktadır. Bu çalışmada öncelikli olarak vincin yükü aldıktan sonraki hareketleri esnasında oluşan salınım hareketi modellenecektir ve modellenen bu salınım hareketi kontrolcülerle denetim altına alınarak minimize edilecektir.

Literatür araştırmaları neticesinde incelenen çalışmalara göre bu çalışmanın farklılıkları öncelikle sensörsüz bir sistem kurulmuş olmasıdır. Bu çalışmada matematiksel modelden, yükün konum bilgileri alını PID kontrolcülerle yük hareketinin kontrollü bir şekilde yapılması sağlanmıştır. Diğer bir farklılık ise çalışma kapasitesinde ( hız olarak) yükün bir yerden bir yere taşınmasında çok fazla bir kayıp yaşanmadan sistemin sonuçlandırılmasıdır. PID kontrolcüler alışılmışın dışında sadece eyleyicilere değil yükün konum bilgileri için de kullanılmış ve yükün hareketine bağlı olan konum bilgisini kontrol eden PID kontrolcüler, eyleyici kontrol eden PID kontrolcülerle ortak çözüm yapılarak istenilen sonuca uygun bir hareket girdisi sağlanmıştır.

\section{VINÇ ve YÜK SALINIMI (CRANE AND SWAY)}

Vinçler çalışmaları sırasında birçok dinamik yükün etkisine maruz kalırlar. Bu dinamik yükler özellikle büyük vinçler için dış etkilerden ve yük salınımlarından kaynaklanmaktadır. Dış etkiler genel olarak rüzgârdan ve gemilerde bulunan vinçler için deniz hareketlerinden kaynaklanmaktadır. İç etkilere ise yükün ve vincin gövdesinin hareketi esnasında oluşan atalet kuvvetleri neden olur. Bu etkiler genellikle kararsızdır ve vinçte titreşimler oluşmasına neden olur. Oluşan bu titreşimler eğer kontrol edilmez veya engellenmez ise iş kazası riskini arttırır ve taşıma işleminin verimini düşürür. Bu nedenle dinamik yüklerin etkisinin azaltılması ve vinçlerin tasarımı yapılırken bu etkilerin hesaba katılması çok önemlidir. Bu dinamik yüklerin etkisini azaltmak için vinç operatörleri taşıma işlemini oldukça yavaş yapmaktadır. Tasarımcılar ise dayanımı artırmak ve yorulmayı azaltmak için vincin yapısını sağlamlaştırarak daha ağır bir yapı oluşmasına izin verirler. Bu nedenle yükün salınım açısının düşürülmesi son derece önemli bir problemdir. Bu problem vinç sistemlerinin salınım kontrolü olarak bilinir ve kontrol mühendislerinin uzun zamandır ilgisini çekmektedir.

Yapı sektöründe ve taşımacılıkta vinçlerin kullanımı gittikçe artmaktadır. Hatta daha büyük, hızlı ve yüksek olmaktadırlar. $\mathrm{Bu}$ da daha etkin kontrol edilmelerini ve daha güvenli olmalarını gerektirmektedir (Abdel-Rahman vd.,2001). Vinçler yaygın olarak ağır ve tehlikeli yüklerin taşınması için gemilerde, fabrikalarda, nükleer santrallerde ve yüksek binaların inşaatında kullanılır. Vinçler 
operasyonlarının konusu yükü bir noktadan bir noktaya en kısa zamanda ve yüksek salınımlar olmadan taşımaktır. Genellikle yetenekli bir operatör bunu yapmaya çalışır (Omar ve Nayfeh, 2003). Vinçlerin işletmeciliğini yapan firmalar, vinçlerin olabildiğince hızlı hareket etmesini ve yapılarının hafif olmasını isterler. Bunu istemelerin nedeni ise taşımacılık maliyetlerinin düşmesini sağlamaktır.

Wei (1993) yaptığı vinç modellerinde şu kabulleri yapmıştır: vincin çelik yapısını tamamen ihmal etmiş, hatta sürtünmelerini ve malzeme sönümlemelerini, rüzgâr etkisini ve hava direncini ihmal etmiştir. Yük hareketini önceden tanımlamış ve sallanmadan bağımsız kabul etmiştir ve halatı ağırlıksız, uzamayan halat olarak almıştır. Birçok aynı varsayımlar Lau ve Low (1994) tarafından taşınabilir bomlu vinçler için yapılmış olan çalışmalarda bulunabilir. Sato ve Sakawa (1988), Yoshimato ve Sakowa (1989) bir yardımcı taşıma kolu ile bomlu vinç modeli önermişlerdir. Burada; varsayımlar şu şekildedir: sadece ana bom ile yardımcı taşıma kolu deforme edilebilir kabul edilir, her taşıma kolunun kütlesi ve kütlelerinin atalet momentleri vardır, dağılmış etkilerin hepsi ihmal edilir, halat deforme edilebilir kabul edilir. Palanganın sallanma açısı kadar yardımcı taşıma kolunun hareketinden kaynaklanan sallanmalar çok küçük açılar olarak kabul edilir. Aynı basitleştirilmeler Moustafa'nın (1994) önermiş olduğu vinç modelinde bulunabilir. Her iki modelde de vincin çelik yapısındaki deformasyonlar ihmal edilmiş ve palanga salınımının açısı küçük kabul edilir. Daha eski modellerde düşey düzlemdeki hareketlerin bütünündeki viskos sönümlemeler palanganın doğal hareketi içinde düşünülür. Yeni modellerde ise bu etki ihmal edilir. Fakat halatın elastik yapısı göz önüne alınır(Jerman, B. vd., 2006).

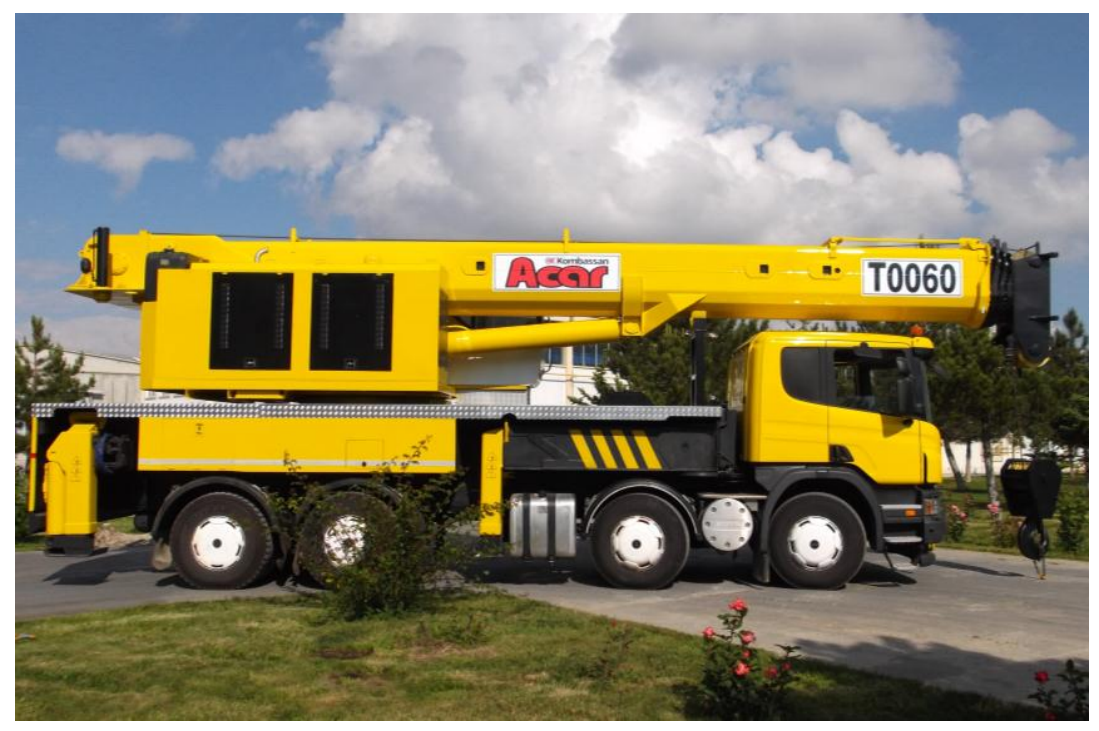

Şekil 1. Mobil hidrolik teleskobik vinç (Mobile hydraulic telescopic crane)

\section{MATERYAL ve YÖNTEM (MATERIAL AND METHOD)}

Bu çalışma kapsamında, Mobil Hidrolik Teleskobik Vinçlerde Yük Salınım sisteminin fiziksel modeli ve hareket dinamikleri; dönüş hareketinin gerçekleştiği bir dikbom, buna bağlı kaldırma hareketinin gerçekleştiği bir anabom, uzatma bomlarının ucunda halat ile konumlandırılmış bir yük tanımlanarak; konum kontrolü yapılmıştır. Sistemin doğrusal olmayan hareket denklemleri Langrangian metoduyla elde edilmiştir. Bu hareket denklemlerinden yola çıkarak, normal sistem davranışı incelenip, durum uzay modeline göre sistemin matematiksel modelli çıkarılmıştır. İlk olarak sistem matlab/simulink ortamında katı modelden alınan veriler referans alınarak modellenmiştir, daha sonra gerçek girdilere göre sinyaller aracılığıyla verilen tahrikler sonucu oluşan salınımı ölçülmüştür. Matematiksel modelden elde edilen sonuçlar ise matlab/simulink ortamına dahil edilerek sistem burada da gerçeklenerek salınım ölçülmüştür. Sistemin kontrolü doğrusal olmayan hareket denklemleri kullanılarak PID kontrolcü ile yapılmıştır. Sistemin PID kontrol cevabı irdelenerek, PID kontrol kazançları belirlenmiştir. P,I ve D kazançlarına göre sistemin kontrol cevapları irdelenmiştir.

Bir matematiksel model çıkarılışına iki farklı yöntemle yaklaşılabilinir. Bunlar;

Kütlesel yaklaşım 
o Dağınık kütle modeli

o Tek bir noktaya indirgenmiş kütle modeli

Düzlemsel yaklaşım

o İndirgenmiş modeli

o Genişletilmiş modeli

Dağınık kütle modeli; yayılı kütle sisteminde sınırı, şartları kaldırma çizgisi boyunca modellenmiş olan halat, kanca, palanga mekanizması ağırlıkları bir noktada toplanarak uygulanır. Tek bir noktaya indirgenmiş kütle modeli; vinç modellerinde çoğunlukla yaygın olarak bu model kullanılır. Kaldırmada kullanılan halat kütlesiz olarak alınır. Kanca ve palanga sistemi tek bir kütle olarak alınır. Halat, kanca ve palanga sistemi küresel bir sarkaç gibi düşünülür. Karmaşık olan palanga sisteminin hareketi basit bir matematiksel ifade ile gösterilir. Bir noktaya toplanmış kütle modelinde iki sınıf vardır. Dış bozuculara bağlı olan sistemi tanımlamaktadır. Bunlar indirgenmiş ve genişletilmiş olarak adlandırılır. İndirgenmiş modelde bir noktadan asılan sarkaç hareketini ifade etmektedir. Bu başlıkta; platform hareketinde palanga sisteminin hareketi etkindir, fakat önemli bir etkinliğe sahip değildir. Bir noktadan asılan bu palanga sisteminin ataleti zaman fonksiyonu üzerinde $\zeta$, $\xi$ ve $\eta$ olarak tanımlanmıştır. Genişletilmiş modele taşıyıcı mekanizmanın ve platformun modeli de eklenmiştir. Genişletilmiş model taşıyıcı mekanizma ile platform arasındaki iç hareketleri ve halat ile palanga sisteminin modelini kapsamaktadır. Bütün indirgenmiş modeller temel bozucuların altındaki küresel sarkaç modeli ile aynı sınıf özelliklerine sahiptir. Diğer bir taraftan, diğer genişletilmiş modeller farklı yapısal özelliklere sahip vinçler ile tek sistemde ele alınır. İndirgenmiş model; Bir noktadan asılan kütleyi; 1 uzunluğunda, m kütlesinde, Kartezyen koordinat sisteminde alırız.

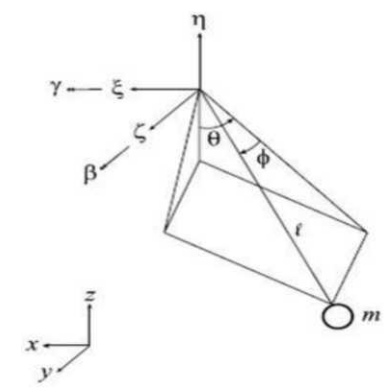

Şekil 2. Noktasal kütlenin koordinat sistemindeki şematik gösterimi(Abdel-Rahman vd., 2001) (Schematic representation of the mass point in the coordinate system( Abdel-Rahman vd., 2001))

Şekil 2 de $[\theta, \beta, \gamma]$ asılı kütlenin dönüş vektörlerini göstermektedir. $\beta$, vincin kalkış açısını ve $\gamma$ ise vincin dönme açını ifade etmektedir. $\theta$ düzlemle yaptığı açıyı, $\varphi$ ise denge konumuna göre yaptığı açıyı belirtmektedir. Bu ifadelerin hepsi t zamanına bağlı olarak değişmektedir. Sarkacın standart modeli ancak halatı esnek olmayan ve uzamayan kabul ettiğimizde geçerlidir.

\section{YÜK SALINIMININ MODELLENMESİ ve KONTROLÜ (SWAY MODELLING AND CONTROL)}

Dikbom uzvu $\theta$ açısı ile $90^{\circ}$, anabom uzvu ise $\beta$ açısı ile $75^{\circ}$ döndürülerek hareket tamamlanmıştır. Vinç uzuvları üzerinden alınan verilere göre; Dikbom uzvunun $\theta$ açısı ile dönme hareketi, anabom uzvunun $\beta$ açısı ile dönme hareketi ve bunların sonucunda halat ucuna asılı yükte oluşan salınım $(\alpha, \gamma)$ langrangian metoduna göre hesaplanarak matematiksel model elde edilmiştir. 


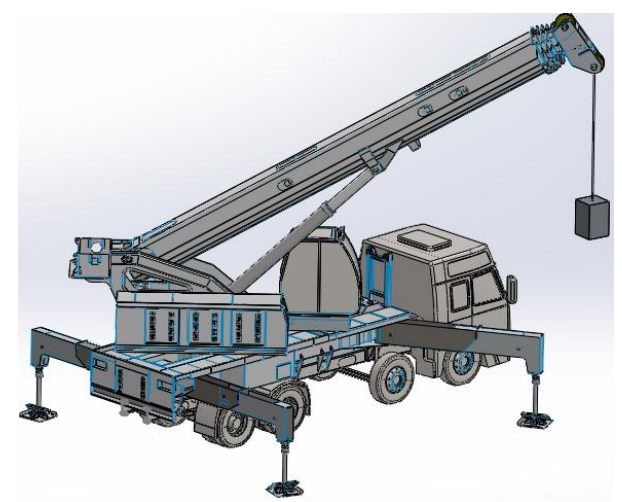

Şekil 3. Mobil hidrolik teleskobik vinç katı modeli (Mobile hydraulic telescopic crane's solid model)

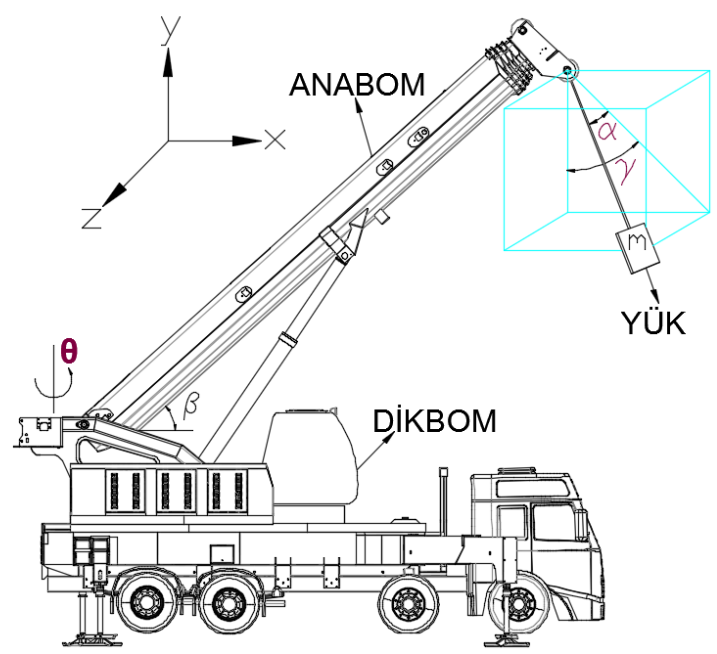

Şekil 4. Vinç uzuvlarının ve yük salınımının şematik gösterimi (Schematic representation of part of the crane and sway of the load )

Çizelge 1. Vinç uzuvlarının teknik özellikleri (The specifications of crane's parts)

\begin{tabular}{|l|l|l|}
\hline$J_{1 y}$ & $\begin{array}{l}\text { Dikbom uzvunun y eksenine } \\
\text { göre atalet momenti }\end{array}$ & $17181,28 \mathrm{~kg} \cdot \mathrm{m}^{2}$ \\
\hline $\mathrm{L}_{1}$ & Anabom boyu & $10,5 \mathrm{~m}$ \\
\hline $\mathrm{J}_{2 z}$ & $\begin{array}{l}\text { Anabom uzvunun z eksenine } \\
\text { göre atalet momenti }\end{array}$ & $200226,5 \mathrm{~kg} \cdot \mathrm{m}^{\wedge} 2$ \\
\hline $\mathrm{M}$ & Anabomun kütlesi & $5713,5 \mathrm{~kg}$ \\
\hline $\mathrm{L}_{2}$ & Halat boyu & $3 \mathrm{~m}$ \\
\hline $\mathrm{m}$ & Yükün kütlesi & $10000 \mathrm{~kg}$ \\
\hline
\end{tabular}

Yükün konumu;

$\mathrm{x}_{\text {ÿ̈в }}=\mathrm{L}_{1} \cdot \cos \beta \cdot \cos \theta+\mathrm{L}_{2} \cdot \sin \alpha \cdot \sin \theta+\mathrm{L}_{2} \cdot \cos \theta \cdot \sin \gamma$

$\mathrm{y}_{\text {ÿ̈k }}=\mathrm{L}_{1} \cdot \sin \beta+\mathrm{h}-\mathrm{L}_{2} \cdot \cos \alpha \cdot \cos \gamma$

$\mathrm{z}_{\text {ÿ̈k }}=-\mathrm{L}_{1} \cdot \cos \beta \cdot \sin \theta+\mathrm{L}_{2} \cdot \cos \theta \cdot \sin \alpha-\mathrm{L}_{2} \cdot \cos \alpha \cdot \sin \theta \cdot \sin \gamma$

Anabom uzvun y eksenine göre atalet moment;

$\mathrm{J}_{2 \mathrm{y}}=-2313 \cdot \beta^{5}+92948 \cdot \beta^{4}-32384 . \beta^{3}-126360 . \beta^{2}+10913 \cdot \beta+97570 \mathrm{~kg} \cdot \mathrm{m}^{\wedge} 2$

Sistemin kinetik enerjisi ;

$\mathrm{T}=1 / 2 \cdot \mathrm{m} \cdot\left(\dot{\mathrm{x}}^{2}+\dot{\mathrm{y}}^{2}+\dot{\mathrm{z}}^{2}\right)+1 / 2 \cdot \mathrm{J}_{1 \mathrm{y}} \cdot \dot{\theta}^{2}+1 / 2 \cdot \mathrm{J}_{2 y} \cdot \dot{\theta}^{2}+1 / 2 \cdot \mathrm{J}_{2 z} \cdot \dot{\boldsymbol{\beta}}^{2}$

Sistemin potansiyel enerjisi ;

$\mathrm{V}=$ m.g. $\left(\mathrm{L}_{1} \cdot \sin \beta-\mathrm{L}_{2} \cdot \cos \alpha \cdot \cos \gamma\right)+\mathrm{M} \cdot \mathrm{g} \cdot \mathrm{L}_{1} / 2 \cdot \sin \beta$ 
Lagrangian denklemi;

$\mathrm{L}=\mathrm{T}-\mathrm{V}$

Hareket denklemleri ;

$\frac{\mathrm{d}}{\mathrm{dt}}\left(\frac{\partial \mathrm{L}}{\partial \dot{\theta}}\right)-\frac{\partial \mathrm{L}}{\partial \theta}=\tau_{1}$

$\frac{\mathrm{d}}{\mathrm{dt}}\left(\frac{\partial \mathrm{L}}{\partial \dot{\beta}}\right)-\frac{\partial \mathrm{L}}{\partial \beta}=\tau_{2}$

$\frac{d}{d t}\left(\frac{\partial L}{\partial \dot{\gamma}}\right)-\frac{\partial L}{\partial \gamma}=0$

$\frac{d}{d t}\left(\frac{\partial L}{\partial \dot{\alpha}}\right)-\frac{\partial L}{\partial \alpha}=0$

Mobil hidrolik teleskobik vince ait dikbom uzvunun çember dişli üzerinde dönme hareketi ve anabomun kaldırma silindiri vasıtasıyla hareketi sonucu, halat ucundaki asılı $10000 \mathrm{~kg}$ lık yükün matematiksel modeli ve diğer uzuvların matematiksel modeli rotasyon matrisi ve langrangian metodu kullanılarak hesaplanmıştır. Çıkarılan matematiksel model, Şekil 5 de görüldüğü gibi matlab/simulink ortamında gerçeklenerek simule edilmiştir.

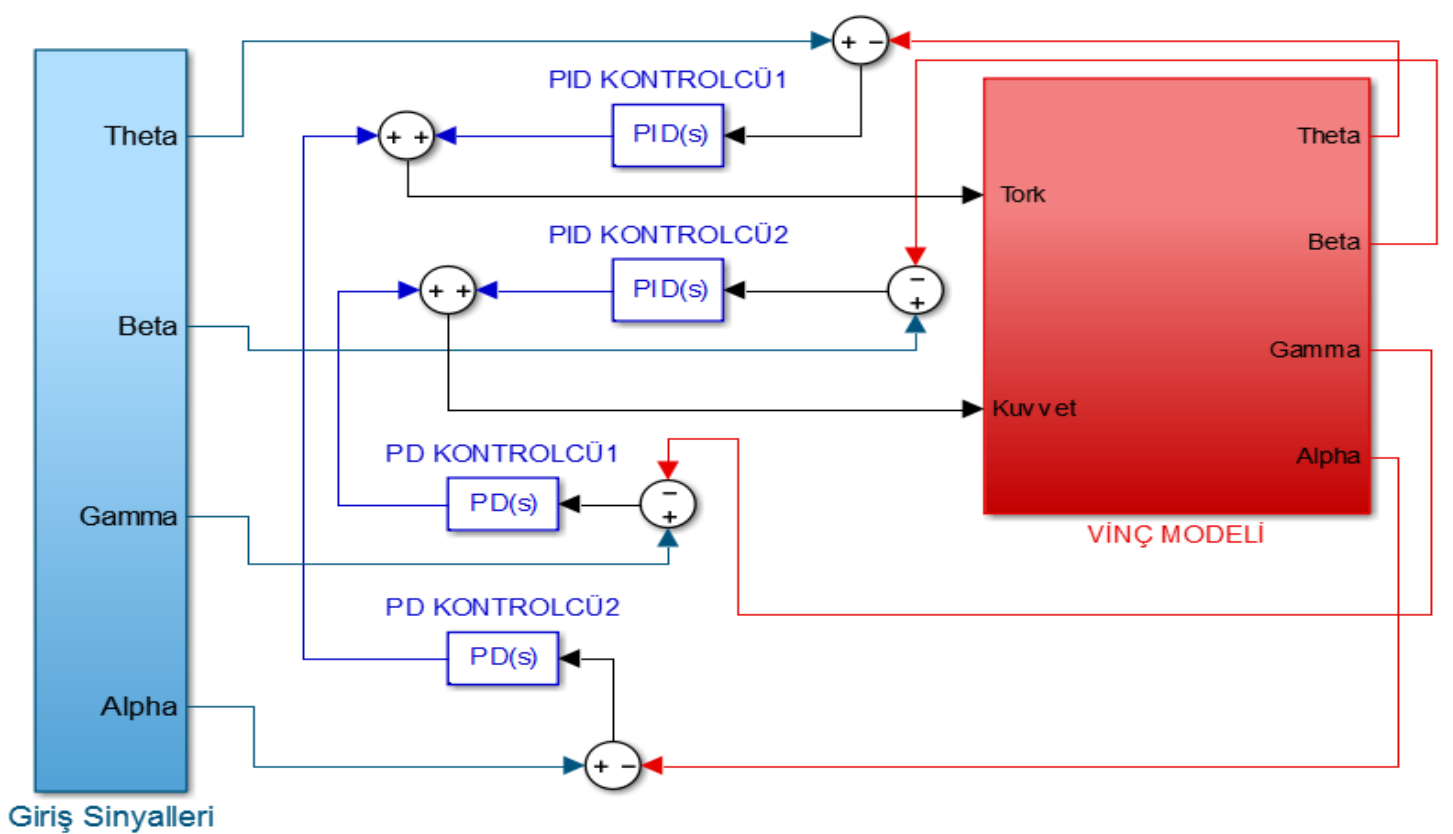

Şekil 5. Mobil hidrolik teleskobik vinç yük salınım modeli ve kontrolü (Sway control and modelling of mobile hydraulic telescopic crane) 


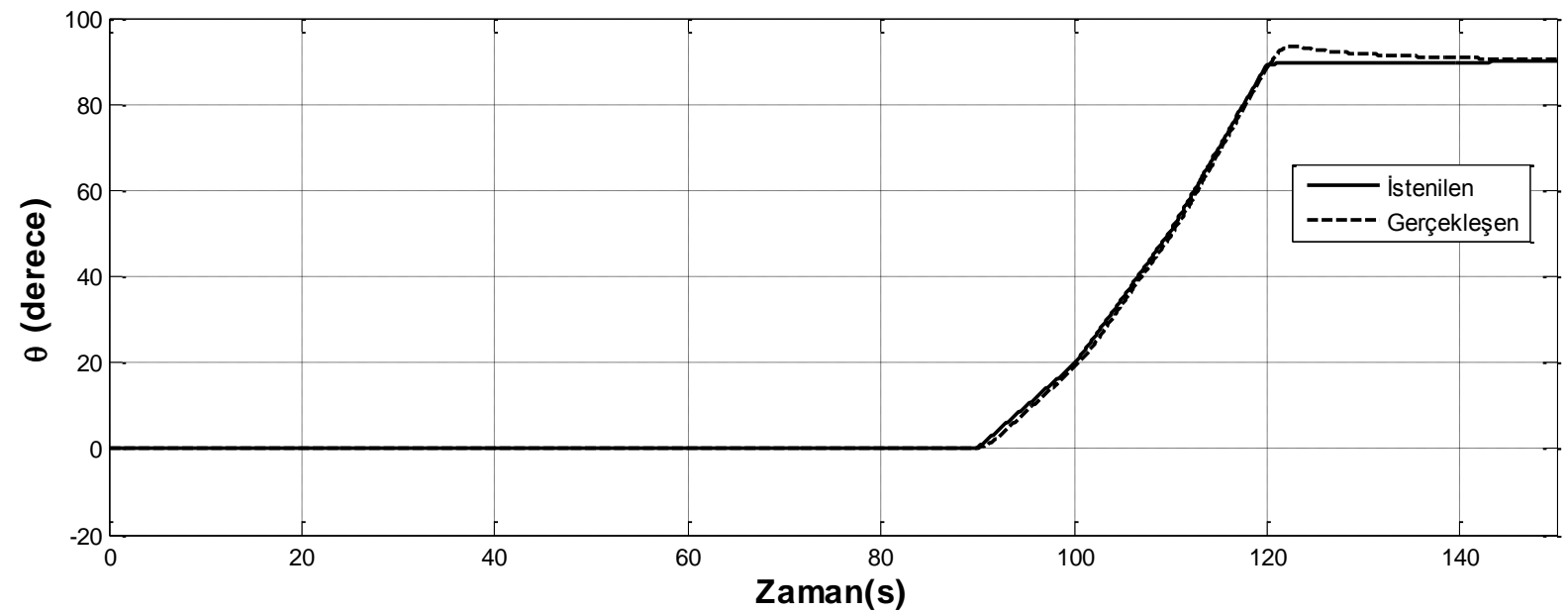

Şekil 6. Dikbom dönüş açısının değişimimi ( Dikbom rotating angle's change)

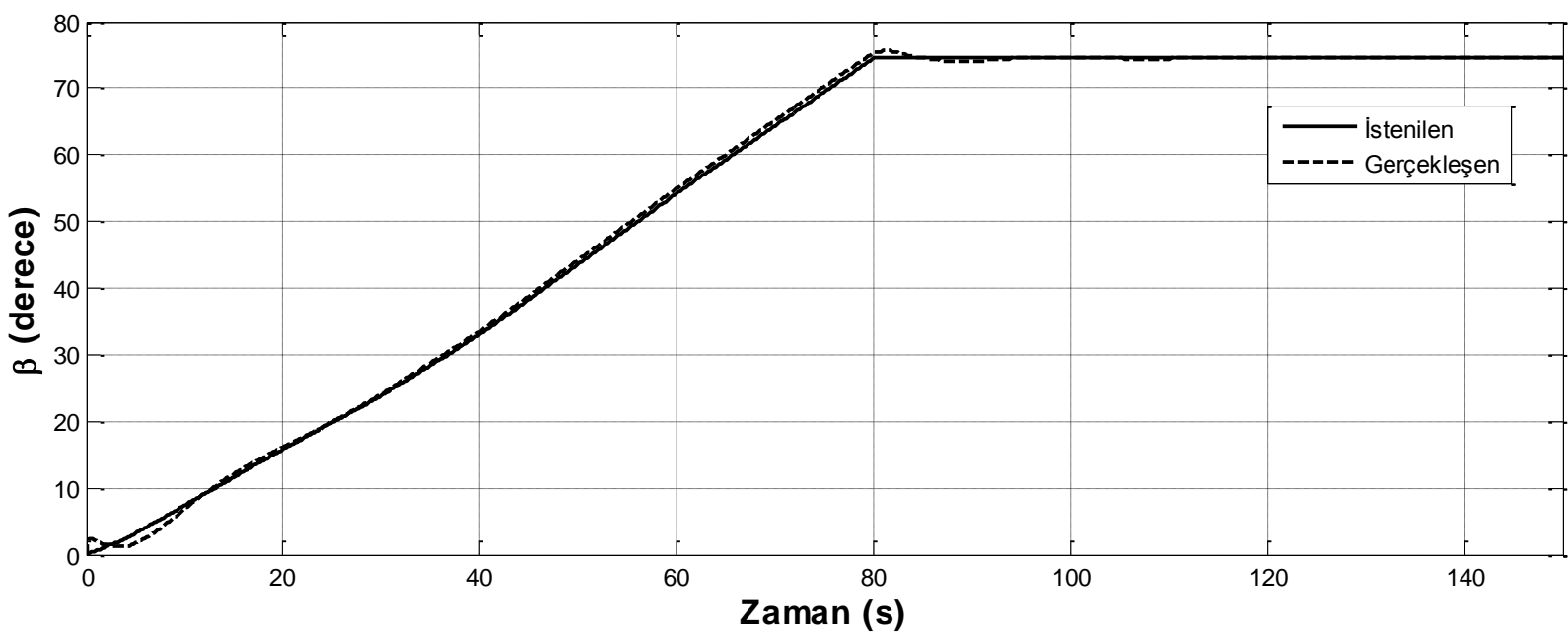

Şekil 7. Anabom dönüş açısının değişimi ( Anabom rotating angle's change)

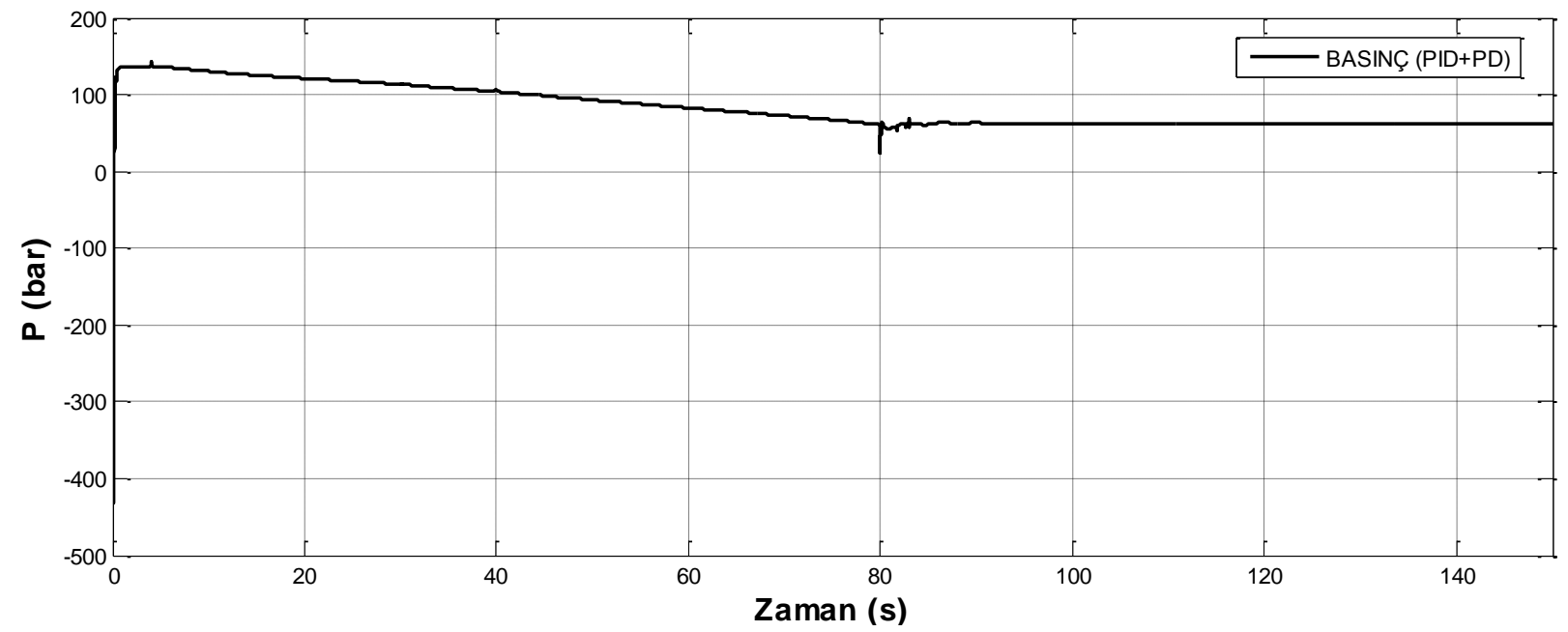

Şekil 8. Anabom kaldırma silindiri basınç değişimi ( Anabom lifting cylinder's pressure change) 


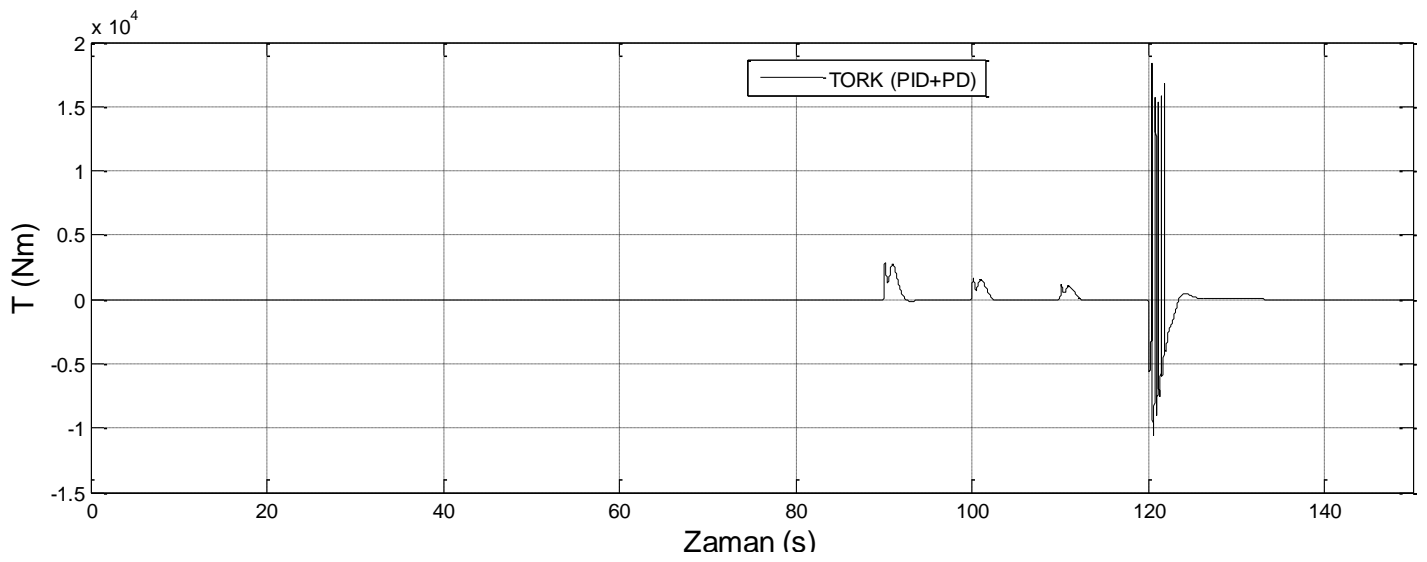

Şekil 9. Dikbom dönüş torku değişimi ( Dikbom rotational torque change)

Şekil 6 ve 7 deki giriş sinyalleri sisteme gönderilerek tahrik kaynaklarının olduğu uzuvlar harekete geçirilmiştir. Sistemden istenilen çıkış değerler ise $\alpha, \gamma$ açılarının, yani yükün yapmış olduğu salınım açılarının " 0 " olmasıdır. Sistemde salınımın kontrolü için PID ve PD kontrolcüler beraber kullanılmış, salınım hareketinin serbest bırakıldığı (kontrolsüz) durumda ise sadece tahrik uzuvlarını konumlandıran PID kontrolcüler kullanılmıştır. İntegral etkisinin ( $\left.\mathrm{K}_{\mathrm{i}}\right)$ kararlı hal hatasının sıfırlanmasında etkisi olsa da geçici tepkinin daha kötü olmasına sebep olmaktadır yani yükselme zamanını azaltsa da aşma değerini artırdığı için salınım açılarının kontrolünde PD kontrolcü kullanılmıştır. Tahrik uzuvlarına bağlı PID kontrolcüler diğer beslemelerle birlikte tork ve kuvvet girdilerini, sistemden istenilen değerlere göre değiştirerek sürekli geri besleme yapmıştır. Şekil 8 ve 9 da bu değiştirilmiş dikbom dönüş torkunun ve anabom kaldırma silindiri basıncının PID+PD kontrolcüleri etkisi altındaki değişim grafikleri verilmiştir. Bu basınç ve tork grafiklerindeki maksimum değerler sistem çalışma kapasitesine uygun değerleridir. Dikbom dönme hareketi, $\alpha$ salınım açısını tetiklediği için buradaki $\alpha$ ya bağlı olan PD kontrolcü2, $\theta$ tahrik açısına bağlı PID kontrolcü1 e besleyici şekilde dahil edilmiştir. 2 kontrolcü ortak çalıştırılarak dikbom dönme hareketi kontrol edilip, sistemden istenilen $\alpha$ giriş açısı elde edilmeye çalışılmıştır. Aynı şeklide bir sistem de anabom uzvunun hareketine uygulanmıştır. Anabom hareketi, $\gamma$ salınım açısını tetiklediği için buradaki $\gamma$ ya bağlı olan PD kontrolcü1 de $\beta$ tahrik açısına bağlı PID kontrolcü2 ye besleyici şekilde dahil edilmiştir. Burada da 2 kontrolcü ortak çalıştırılarak anabom hareketi kontrol edilip, sistemden istenilen $\gamma$ giriş açısı elde edilmeye çalışılmıştır. Sistem çalıştırılırken teleskobik vinç çalışma kapasiteleri de göz önünde bulundurulup modelleme ve kontrol gerçeklenmiştir. PID ve PD kontrolcü kazanç parametreleri ( $\mathrm{K}_{\mathrm{p}}, \mathrm{K}_{\mathrm{i}}$, ve $\mathrm{K}_{\mathrm{d}}$ ) en uygun sistem cevabı için öncelikle matlab/simulink ortamında PID Tune ile ayarlanıp daha sonra deneme yanılma yoluyla optimize edilerek bulunmuştur.

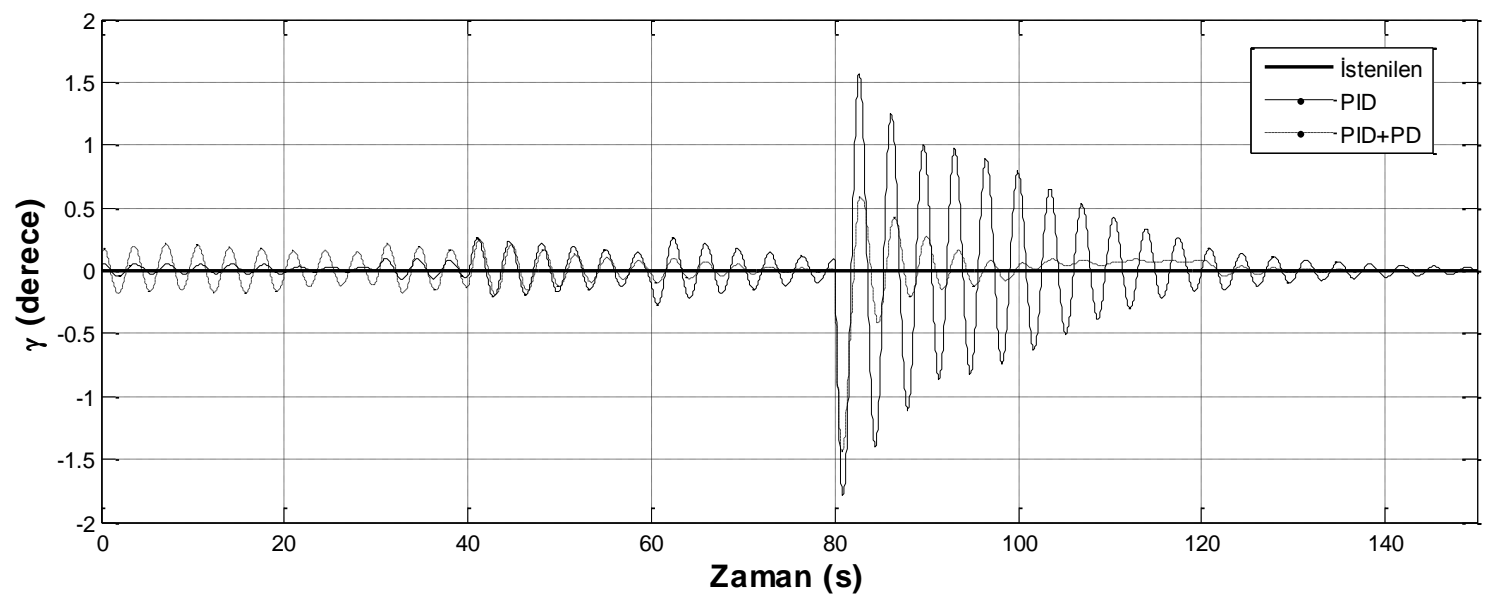

Şekil 10. $\gamma$ salınım açısının PID kontrollü ve PID+PD kontrollü değişimi $(\gamma$ sway angle's change of the PID controlled and PID+PD controlled) 


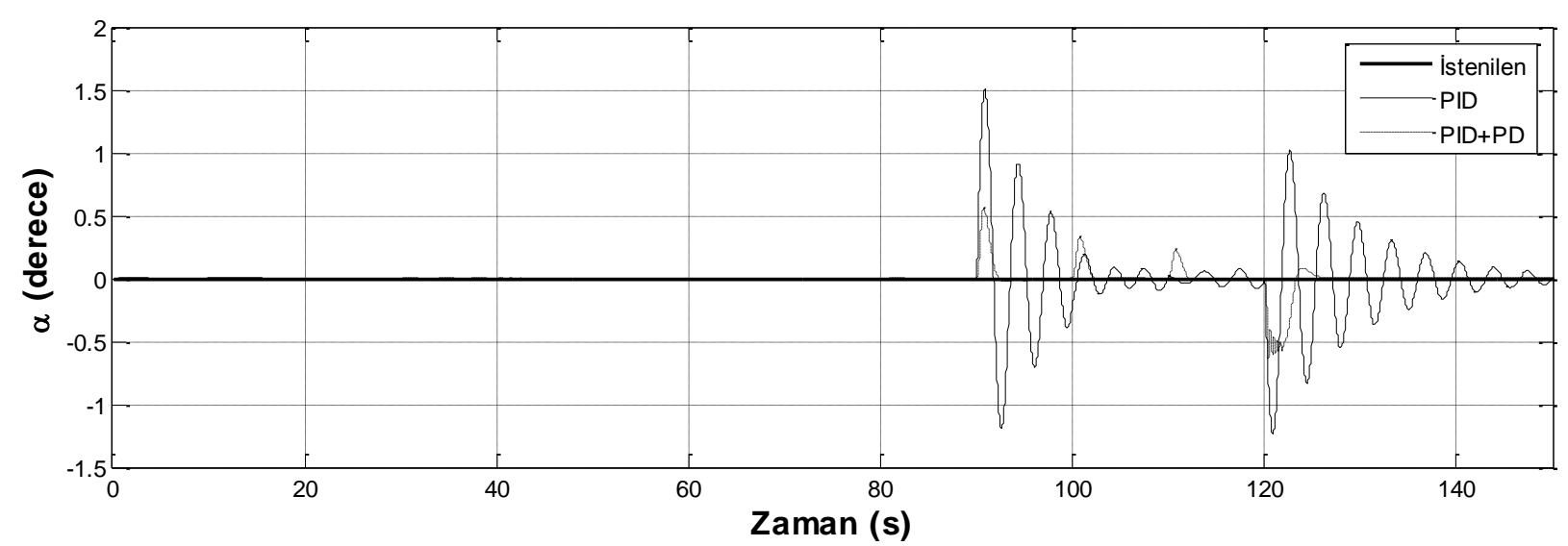

Şekil 11. $\alpha$ salınım açısının PID kontrollü ve PID+PD kontrollü değişimi $(\alpha$ sway angle's change of the PID controlled and PID+PD controlled)

Şekil 10 ve 11 de $\alpha$ ve $\gamma$ açılarının PID+PD kontrolcü uygulanmış ve PID kontrolcü uygulanmış durumlarındaki sistem cevapları görülmektedir. Yalnızca PID kontrolcü olan sistemde 90. saniyede yani anabom kalkma hareketinin bitip dikbom dönme hareketinin başladığı anda $\alpha$ ve $\gamma$ açılarının ani artış gösterdiği ve bu artışın 130. saniyeye kadar devam ettiği görülmektedir. Her iki açının da $1,5^{\circ}$ ye ulaştığ 1 gözlemlenmektedir. Bu açı değerinin yükün asılı olduğu halat uzunluğu göz önüne alındığında büyük bir değer olduğu belirlenmiştir. PID ve PD kontrolcüler sisteme dahil edildiğinde ise $\alpha$ salınım açısı, hareket başlangıç anında $0,5^{\circ}$ ve $90-120$ saniye arasında 0 a yakın değerlerde ilerlemiş, 120 . Saniyede sistemin durmak üzere yavaşlamasıyla yükün kütle atalet momentinden dolayı tekrar $0,5^{\circ}$ ye gelmiştir. Fakat 5 saniyede bu salınımın sönümlendiği gözlemlenmektedir. Diğer salınım açısı $\gamma$ nın ise $0-80$ saniye arası sürekli fakat $\pm 0,2^{\circ}$ dolaylarında osilasyona girdiği gözlemlenmektedir. Hareketin durma noktası olan 80. saniye sonrasında yine yükün atalet momenti salınımı $1^{\circ}$ ye çıkarmıştır. Fakat PID+PD kontrolcü ile 10 saniyede sönümlenerek salınım istenilen açıda tutulmuştur.

\section{SONUÇ ve TARTIŞMALAR (RESULTS and DISCUSSIONS)}

Bu çalışmada mobil hidrolik teleskobik vincin dikbom dönme hareketi ve anabom kalkma hareketi sonucu anabom ucunda halat ile asılı olan yükün salınım açlarını kabul edilebilir değerlere getirmek amacıyla PID kontrolcü tasarımları yapılmıştır. Tasarımı yapılan kontrolcülerin kullanılması ve kullanılmaması durumlarına ait sayısal ve grafiksel simulasyonlar elde edilerek karşılaştırmaları yapılmıştır.

Öncelikli olarak sistem uzuvları dikkate alınarak matematiksel model çıarılmıştır. Daha sonra sistemin istenilen sinyaller ve değerlere göre kapalı çevrim kontrolü yapılmıştır. Tahrik uzuvlarının kontrolü için PID kontrolcü, salınım açılarının kontrolü için ise PD kontrolcü seçilmiştir. PD kontrolcüler bir tahrik oluşturamadığı için buradan alınan veriler PID kontrolcülere verilerek tahrik uzuvlarında tork ve basınç değişimleri sağlanmıştır. Sistem PID+PD kontrolcü uygulanmış ve PID kontrolcü uygulanmış durumlarına göre karşılaştırılmıştır. PID+PD kontrolcünün sistem üzerinde oldukça etkili olduğu ve istenilen cevaba uygun değerler verdiği tespit edilmiştir. Yükün yapmış olduğu salınımın vinç operatörü tarafından ayarlanmaya çalışılmasının önüne geçilmiş ve daha hassas saha çalışmalarının yapılabileceği görülmüştür. Bu yöntem ile yük salınımlarının sebep olabileceği iş kazalarının da önüne geçilebileceği görülmüştür. Literatür çalışmalarına göre kıyaslama yapıldığında bu tür salınım kontrollerinde daha çok bulanık mantık yöntemiyle çalışmalar mevcuttur. Bu çalışma PID kontrolcülerinde içinde bulunduğu sensörsüz salınım kontrolü olarak diğer çalışmalardan daha avantajlı olmaktadır. Yapılan çalışmada salınım açısının eldesi olarak, hayali sensör sistem matematiksel modelinden elde edilen bilgilerle sağlanmıştır. Sensörlü sistemlerde maliyet ve entegrasyon sorunları bulunmaktadır. 
$\mathrm{Bu}$ çalışmada sayısal uygulama yapılabilmesi için gerekli olan gerçek bir sisteme ait verilerin teminindeki katkı ve desteklerinden dolayı tüm MPG A.Ş. çalışanlarına ve Genel Müdürü Veysel ALVER ‘e teşekkür ederiz.

Bu makale Umut YILMAZ 'in yüksek lisans tezinden türetilmiştir.

\section{KAYNAKLAR (REFERENCES)}

Abdel-Rahman, E. M., Nayfeh, A. H. Ve Masoud, Z. N.,(2001), " Dynamics and Control of Cranes: A Review ", Journal of Vibration and Control, 9:863-908, Sage Publications.

Omar, M. H. Ve Nayfeh, A. H. , (2003), "Gain Scheduling Feedback Control of TowerCranes with Friction Compensation ", Journal of Vibration and Control, 10:269-289, Sage Publications.

Wei, L., Zhixin, W., Baoliang, Q., Shijun, S., Caishan, L., (1993), "The mathematical model of the Load vibration-sway on fixed type tower cranes", Modeling, Measurement \& Control B: Solid \& Fluid Mechanics \& Thermics, Mechanical Systems, Robotics, Civil Engineering, 51(3):1-12.

Lau, WSM. ve Low, KH., (1994) "Motion analysis of suspended mass attached to a crane", Computers and Structures, 52(1):169-78.

Sato, K. ve Sakawa, Y., (1988), "Modeling And Control Of A Flexible Rotary Crane", Internatinal Journal Of Control, 48(5):2085-2105.

Yoshimoto, T. ve Sakawa, Y.,(1989), "Modeling and control of a rotary crane with a Jexible joint", Optimal Control Applications and Methods, 10:21-38.

Moustafa, KAF, (1994), "Feedback control of overhead cranes swing with variable rope length",

Proecedings of the American Control Conference, 1:691-695

Jerman, B. (2006)," An Enhanced Mathematical Model For Investigating The Dynamic Loading of a Slewing Crane", Proceedings of The Institution of Mechanical Engineers, Apr 2006 220,C4;ProQuest Science Journals, 421. 